\title{
Small-Scale Spatial Inhomogeneities in X-Ray Fluxes in Auroral Stratosphere
}

\author{
A.M. Novikov, Yu. G. Shafer, and R.F. ZhDanov \\ Institute of Cosmophysical Research and Aeronomy, Yakutsk Branch, \\ Siberian Department of the U.S.S.R. Academy of Sciences, \\ Yakutsk, U.S.S.R.
}

(Received February 7, 1978)

Synchronous balloon measurements of X-rays in the stratosphere were carried out at Tixie Bay $\left(71.6^{\circ} \mathrm{N}, 128.9^{\circ} \mathrm{E}\right)$ in March 1975 and 1976 . Typical balloon separation distances were $20-200 \mathrm{~km}$. These X-ray measurements correspond to the high energy tail of the precipitating electron flux $\left(E_{e} \sim E_{x} \sim\right.$ hundreds of $\left.\mathrm{keV}\right)$.

From Fig. 1 it is seen that electron precipitation into the upper atmosphere on March 18, 1975 was present for many hours as determined by the measurement of the ionospheric absorption of cosmic radionoise at a frequency of $32 \mathrm{MHz}$. The magnitude of the absorption is given in Fig. 1. Maximum absorption amplitude was $3.5 \mathrm{db}$. Detection of X-rays was carried out from $12 \mathrm{hr} 30 \mathrm{~min}$ to $12 \mathrm{hr} 55 \mathrm{~min}$ during the recovery phase of the absorption. X-ray fluxes had small intensities and were not correlated with local magnetic activity. Only a negative magnetic bay with amplitude $400 \gamma$ ( $H$-component) was observed, $10 \mathrm{hr}$ after the detection of emission in stratosphere.

In Fig. 1 the simultaneously detected X-ray fluxes are divided into two parts. There is good temporal correspondence of X-ray fluxes at the spaced balloons, during $a-b$, while the portion $b-c$ has no correspondence. During the incoherent detection of X-ray fluxes the balloons drifted at $25 \mathrm{~km}$ altitude and were spaced $30 \mathrm{~km}$ from each other. A large magnitude X-ray flux was measured by a detector placed $5 \mathrm{~g} / \mathrm{cm}^{2}$ below the second detector. In the lower part of Fig. 1 a sketch of the balloon positions (projected on the Earth) during the X-ray measurements for two times $12 \mathrm{hr} 35 \mathrm{~min}$ and $12 \mathrm{hr} 45 \mathrm{~min}$ is given. The projection on the Earth of the sensing area of the riometer is also given. Thus, on March 18, 1975, small-scale spatial inhomogeneities in X-ray flux during the period $b-c$ were observed. The difference in $\mathrm{X}$-ray flux amplitude, and the incoherence of their temporal variations, existed at distances of $30 \mathrm{~km}$ in the stratosphere. On the other hand, the radiation during the period from $a$ to $b$ is coherent. Some difference in amplitude is due to differing altitudes of balloon flights. This fact can be used to estimate the mean energy of the X-ray quanta on the basis of the well-known Lambert law.

$$
\mu f\left(E_{x}\right)=\ln \frac{I_{1}}{I_{2}} \cdot x^{-1},
$$




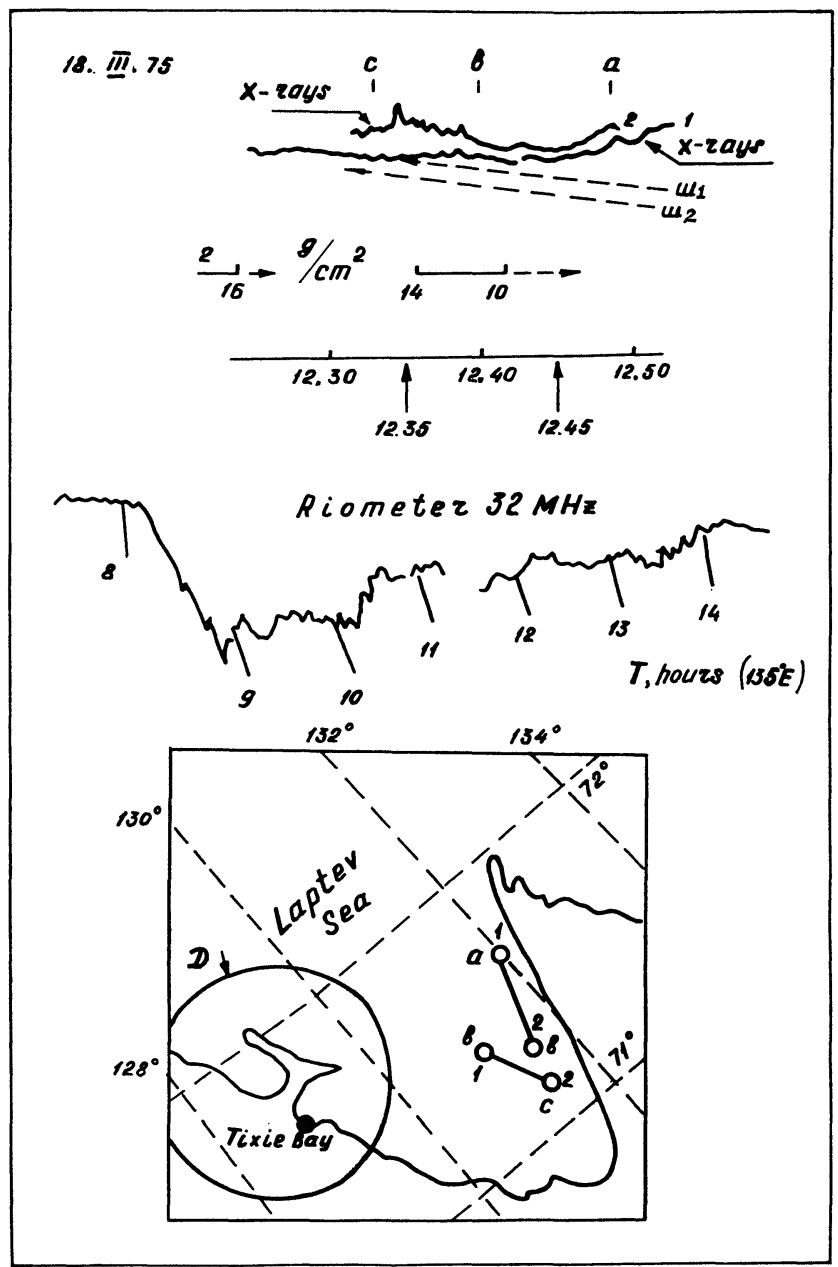

Fig. 1. Temporal variations of X-ray flux in stratosphere over Tixie Bay on March 18, 1975 at two observation points.

where $\mu$ is a mass coefficient of X-ray absorption in the air, $E_{x}$ is the energy, $I_{1}$ and $I_{2}$ are magnitudes of X-ray fluxes at various altitudes in stratosphere. $x$ is the quantity of atmosphere substance between detectors along the vertical. The dependence $\mu f\left(E_{x}\right)$ is taken from Goldstein (1961). The calculations show that X-ray rigidity in the coherent interval grows with time (Fig. 2).

An example of the existence of spatial peculiarities in X-ray flux at distances $50-100 \mathrm{~km}$ is given in Fig. 3. Results of X-ray measurements by a Geiger counter and of the cosmic ray background with a 'telescope' on the first balloon are presented in the upper part of Fig. 3. The X-ray flux obtained on the second balloon is in the lower part of Fig. 3. In Fig. 3 are also given: flight altitudes of both balloons in $\mathrm{mb}$, the registration type scale (with point 180.27 and $52.67 \mathrm{~min}^{-1}$ for the Geiger counter and $11.02 \mathrm{~min}^{-1}$ for 'telescope' in the first flight; 50.4 and $199.4 \mathrm{~min}^{-1}$ for 


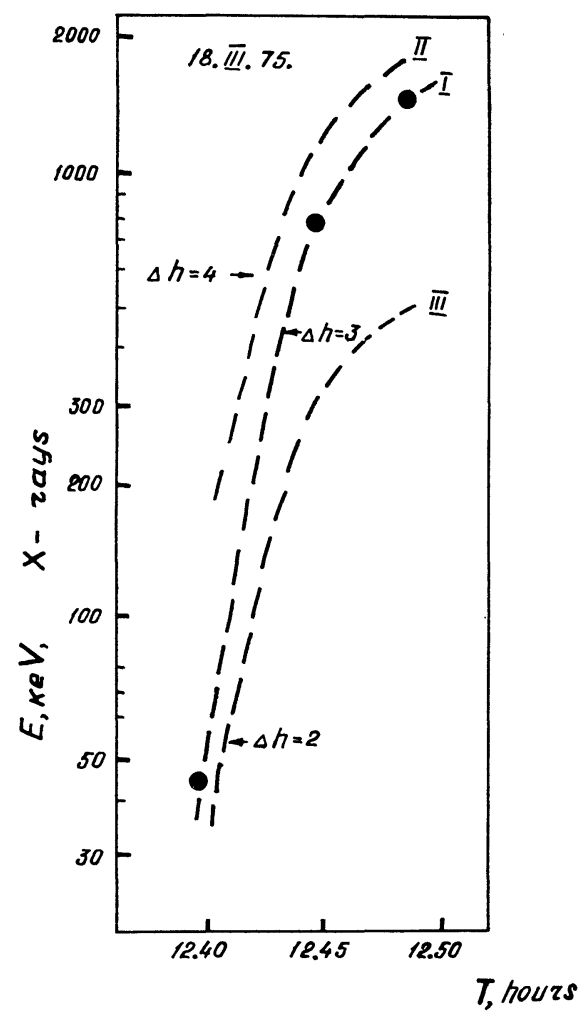

Fig. 2. Temporal variations of the energy of X-ray quanta in stratosphere over Tixie Bay on March 18, 1975. $\Delta h$ : Amount of atmosphere between detectors along the vertical in $\mathrm{g} / \mathrm{cm}^{2}$. Accuracy of determination $\Delta h: \pm 1 \mathrm{~g} / \mathrm{cm}^{2}$.

the Geiger counter in the second flight), the sketch of the positions of the balloons $\omega 1-\omega 2$ (projected on the Earth) and the riometer measurements. The absorption at the first minute of each hour is given in $\mathrm{db}$. Dark rectangles show the time of measurements in the stratosphere on the two balloons, ' $\mathrm{K}$ ' is a moment of calibration of the riometers.

The onset of intense precipitation on March 2, 1976 was recorded on the two balloons simultaneously at $12 \mathrm{hr} 59 \mathrm{~min}$ at an altitude of $25 \mathrm{~km}$. But the growth rate of X-ray counts on the two balloons was different. During $13 \mathrm{hr} 03 \mathrm{~min}-$ $13 \mathrm{hr} 13 \mathrm{~min}$ the growth rate of X-ray counting on the first detector was $115.4 \mathrm{~min}^{-1}$; and on the second detector $-1320.62 \mathrm{~min}^{-1}$. Gradients of X-ray growth rate at locations separated from each other by distances $50-100 \mathrm{~km}$ became smaller with time. During $13 \mathrm{hr} 12 \mathrm{~min}-13 \mathrm{hr} 15 \mathrm{~min}$ they were 192 and $465 \mathrm{~min}^{-1}$, respectively, i.e., small-scale spatial features in X-ray fluxes as in the case on Mach 18, 1975 were less noticeable. 


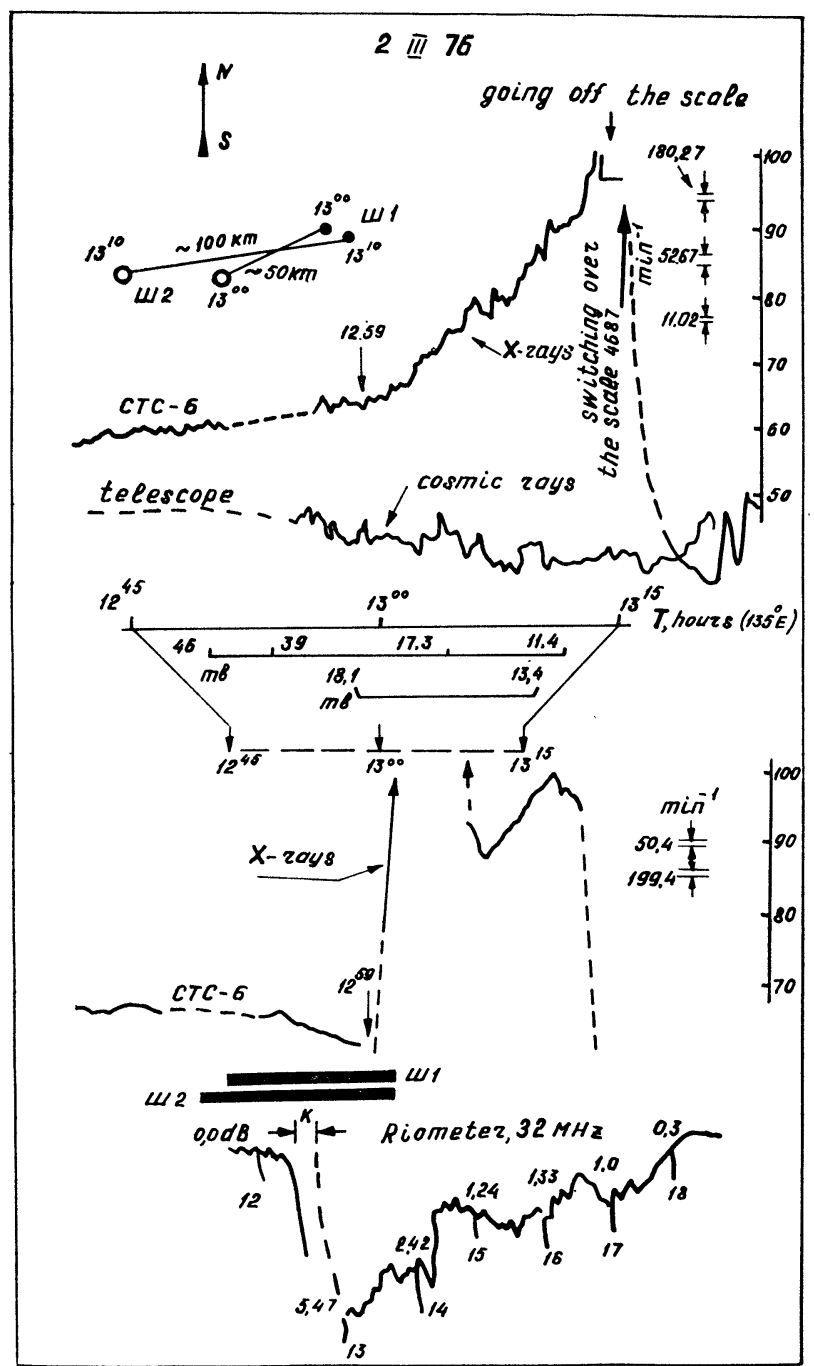

Fig. 3. The X-ray flare registered in stratosphere on separated balloons on March 2, 1976.

\section{REFERENCE}

Goldstein, G., Osnovy zaschity reaktorov. Gosatomizdat, Moscow, p. 135, 1961. 